Article

\title{
The Alphabet Effect Re-Visited, McLuhan Reversals and Complexity Theory
}

\author{
Robert K. Logan \\ Department of Physics, University of Toronto, 60 St. George, Toronto, ON M5S 1A7, Canada; \\ logan@physics.utoronto.ca; Tel.: +1-416-361-5928 \\ Academic Editor: Marcin J. Schroeder \\ Received: 2 November 2016; Accepted: 22 December 2016; Published: 3 January 2017
}

\begin{abstract}
The alphabet effect that showed that codified law, alphabetic writing, monotheism, abstract science and deductive logic are interlinked, first proposed by McLuhan and Logan (1977), is revisited. Marshall and Eric McLuhan's (1988) insight that alphabetic writing led to the separation of figure and ground and their interplay, as well as the emergence of visual space, are reviewed and shown to be two additional effects of the alphabet. We then identify more additional new components of the alphabet effect by demonstrating that alphabetic writing also gave rise to (1) Duality, and (2) reductionism or the linear sequential relationship of causes followed by effects. We then review McLuhan's (1962) claim that electrically configured information reversed the dominance of visual space over acoustic space and led to the reversals of (1) cause and effect, and (2) figure and ground. We then demonstrate that General System Theory first formulated by Ludwig von Bertalanffy (1968), which also includes chaos theory, complexity theory and emergence (aka emergent dynamics) and Jakob von Uexküll's (1926) notion of umwelt also entail the reversal of many aspects of the alphabet effect such as the reversals of (1) cause and effect, and (2) figure and ground.
\end{abstract}

Keywords: alphabet effect; emergence; figure; ground; alphabet; monotheism; science; logic; codified law

\section{Origin of the Alphabet Effect}

McLuhan and Logan (1977) [1] in a paper entitled Alphabet, Mother of Invention suggested that the alphabet explains why Western thought patterns are highly abstract, compared with Eastern thought. They pointed out that there developed in the very narrow geographic zone between the Tigris-Euphrates river system and the Aegean Sea, and within the very narrow time frame between 2000 B.C. and 500 B.C. a group of innovations that constitute the basis of Western thought. These innovations included the phonetic alphabet first invented by the Seirties or Kennites living in the South Sinai desert, codified law developed by the Babylonians, monotheism inaugurated by the Hebrews, abstract theoretical science and deductive logic first introduced by the ancient Greeks. McLuhan and Logan did not suggest a direct causal connection between these innovations. Instead they suggested that that these innovations created an environment that supported their mutual development, given that these cultures, which gave rise to these developments, were in direct communication and traded with each other.

\section{The Emergence of Visual Space and the Detachment of Figure and Ground and Their Interplay}

Eric and Marshall McLuhan (1988) [2] (pp. 18-19) identified another effect of the alphabet namely the emergence of visual space and the subsequent detachment of figure and ground in which the figure comes into greater prominence and the ground receded to the point that it becomes subliminal (Lior Lerman private communication) [3]. 
The most remarkable quality of the alphabet is its abstractness of various kinds. From the patterns of separation, of ensibilities, and of figure from ground, with the subsequent suppression of ground, comes the character of stasis, one of the four features of visual space. When figure and ground are in interplay, they are in dynamic relation, continually modifying each other. Thus, stasis of the figures can only be achieved by detaching them from their ground, and is the necessary result of detachment. The sounds and sign of the phonetic alphabet are in no dynamic relation or interplay; one simply stands for the other. Both are abstracted from all meaning or relation. Oral, resonant speech is broken into irreducible (uniform) bits of meaningless sound, each connected to a sign by arbitrary association, and by uniform orthography. By means of a continuous linear sequence of signs, the bare sounds that compose speech are re-presented and re-cognized through a single sense in isolation. From this static, connected figure-detached-from-ground character, the alphabet derives its other great power of abstraction, that of translating into itself (as an abstract, unmodified/unmodifying container) the sound-systems of other languages.

Although claiming that figure and ground become detached and ground becomes subliminal, Marshall and Eric McLuhan [2] (p. 5) still claim that nevertheless figure and ground interact with each other:

All situations comprise an area of attention (figure) and a very much larger area of inattention (ground). The two continually coerce and play with each other across a common outline or boundary or interval that serves to define both simultaneously. The shape of one conforms exactly to the shape of the other. Figures rise out of, and recede back into, ground, which is con-figurational and comprises all other available figures at once ... In the order of things, ground comes first and the figures emerge later. 'Coming events cast their shadows before them'. The ground of any technology or artefact is both the situation that gives rise to it and the whole environment (medium) of services and disservices that it brings into play.

\section{Figure/Ground: Cracking the McLuhan Code}

The relationship of figure and ground and their interplay is a recurring and central theme of Marshall McLuhan's understanding of media as pointed out by Logan (2011) [4] in an article entitled "Figure/Ground: Cracking the McLuhan Code", where it is argued when McLuhan compares the following couplets one is the figure and the other is the ground:

- In the reversal of cause and effect it is the effect that is the ground and the cause that is the figure...

- In the relationship of jobs and roles it is the role that is the ground and the job that is the figure. 'Goal seeking' is figure and 'role-playing' is ground;

- In the consideration of percepts and concepts it is the percept that is the ground and the concept that is the figure;

- In 'the medium is the message' it is the medium that is the ground and the message or content that is the figure;

- In 'the user is the content' it is the user that is the ground and the content that is the figure;

- In 'every technology has both service and disservice' it is the disservice that is the ground and the service that is the figure;

- In 'products become services in the electric age' it is the service that is the ground and the product that is the figure;

- In 'consumers become producers in the electric age' it is the consumer that is the ground and the producer that is the figure;

- In contrasting a point of view with pattern recognition it is the pattern recognition that is the ground and the point of view that is the figure. 
In each of these figure/ground relationships the interactions between figure and ground are exactly as they were described in the previous section, namely that they "are in interplay, they are in dynamic relation, continually modifying each other [2] (p. 18)".

\section{Alphabet, Deductive Logic, Duality and Reductionism}

We would like to propose another effect of the alphabet in addition to the ones identified by McLuhan, M. and Logan (1977) [1] and McLuhan, M. and E. (1988) [2]. We suggest that another effect of the alphabet was to give rise to a form of duality, that is characteristic of Western alphabetic culture, namely constitutional duality. Before establishing this connection, we need to differentiate between the different forms of duality. There is binary dualism such as distinguishing between being and non-being as in deductive logic, it is a duality which arises out of grammatical necessity. There is also a closely related duality, polarity duality, of opposites such up and down; left and right; forward and backward; hot and cold; good and evil; light and dark; and yin and yang. There is also constitutional dualism as (1) mind and body in the context of the philosophy of mind; (2) God and his creations or the physical universe; and (3) material reality and spiritual reality as described in many religions. Binary and constitutional duality are characteristic of Western alphabetic cultures. The third duality of polarity is found in all cultures. An example of polar dualities is the notion of yin and yang of Taoism found in many East Asian non-alphabetic cultures. Yin and yang are seemingly opposite but yet at the same time they are complementary, interconnected and interdependent. The very graphic design of yin and yang as represented in Taoism represents the intertwining of yin and yang as represented in this image:

In Western binary and constitutional duality, the boundaries are impermeable and the two poles of the dual relationship are quite independent of each other unlike the relationship of yin and yang.

We believe that binary and compositional forms of Western dualism are interconnected and are the effect of alphabetic writing. Binary duality is an absolute presupposition of deductive logic and deductive logic is one of the effects of alphabetic writing as noted by McLuhan and Logan (1977) [1].

The connection between the alphabet, binary duality and constitutional duality is not a direct one but one that can be established if one first accepts that there is a connection between the alphabet and deductive logic as argued by McLuhan and Logan (1977) [1]. Alphabetic writing encouraged the development of deductive logic because the alphabet promotes representing spoken words with a linear combination of meaningless visual signs representing phonemes assembled in the correct order. Every spoken word is first analyzed into its constituent phonemes and then those phonemes are represented by the meaningless signs of the alphabet and arranged in a logical order. This created an environment in which arguments were assembled in a similar linear sequential logical order. Rationality trumped poetics and so the arguments of the sophists were looked down on because they appealed to the emotions rather than the cold hard facts of a logical argument.

The pervasive use of uniform elements, the phonetic letters that the alphabet entailed, encouraged the additional visual matching of situational elements which formed the ground for Greek logic, geometry, and rationality. The idea of truth itself, the correspondence of thing and intellect, is based on matching ... The Greek alphabet also provided both the model and the bias for classification, an essential development in Greek analytic thought during the period from 700 to 400 B.C.- - especially for logic, science, and history. In addition to serving as a paradigm of abstraction and classification, the alphabet also served as a model for division and separatability. [1]

The Greeks applied the use of logic to create proofs of the geometric relationships that the Egyptians arrived at empirically. They were bedazzled with their new found technology of deductive 
logic to the point that a separation of rationality from common sense took place. It started with Parmenides who used logic to argue that nothing changes because if A were to change into $\mathrm{B}$, then A would not-be and since non-being cannot be (it is a logical contradiction) nothing changes. Parmenides argument used a form of duality that entails a binary either or division but then he uses deductive logic to conclude that nothing changes and hence laid the ground work for the emergence of substance/essence dualism, a form of constitutional dualism formulated by Plato.

The idea that nothing changes was clearly in contradiction to the common sense observation of the changes in one's everyday experiences. Plato found a way to resolve this apparent paradox and the solution was to invoke a form of substance/essence dualism and thereby created two worlds. There is the essence world of the Ideal Forms that are never changing as Parmenides required and the everyday substance world that one perceives in everyday life, which Plato likened to shadows on the wall of a cave cast by the fire burning within the cave and do change as common sense reveals and demands. Plato took his cue from Parmenides who wrote "Whence it follows that all things to which men attribute reality, generation and destruction, being and not-being, change of place, alteration of colour are no more than empty words (http:/ / philoctetes.free.fr/parmenides.htm) [5]".

Plato with help from Parmenides separates percepts from concepts and this dualism becomes enshrined in Western philosophical thought. Parmenides version of binary dualism and his use of deductive logic led to Plato's constitutional dualism of the world of Ideal Forms and the everyday world of perceptions. These two domains are not opposites just as mind and body are not opposites in mind/body dualism. But what is being suggested here is that Plato's constitutional dualism resolved the paradox that there is no change in Parmenides world whereas change is the pervasive property of the world of every day experience.

Parmenides and Plato's dualities had the unfortunate effect of killing off the empirical spirit of the pre-Socratics like Anaxagoras, Anaximander and Heraclitus. Heraclitus proclaimed "The things of which there can be sight, hearing and learning-these are what I especially prized (the very opposite of Parmenides' position). Men who love wisdom should acquaint themselves with a great many particulars. Seekers after gold dig up much earth and find little". Anaxagoras having observed that meteorites that came from heaven were made of rocks concluded that heavenly bodies were also composed of rocks. Anaximander on the basis of observing the gills on a miscarried human fetus argued for evolution more than 2000 years before Darwin. The empirical spirit of the pre-Socratics was undermined by the logical arguments of Parmenides and Plato. Even Aristotle contributed to the undermining of empiricism. He argued against inertia saying that an object dropped from the mast of a ship would fall behind the mast in the opposite direction of the ship's motion. If he only had climbed to the top of a mast and performed the experiment or asked a mariner to do it he would have discovered that his argument was wrong. These were the roots of the duality that divided the world into two spheres, the one perceived and the one conceived.

The tradition of duality even survived the scientific revolution and empirical spirit of Galileo, Borelli, Brahe, Kepler and Newton. Descartes, himself a mathematician and scientist, whose development of analytic geometry led to Newton's calculus, divided the world into two domains the material and the spiritual. Cartesian duality paralleled Plato's division of the two realms, the material world of every day experience and the realm of Ideal Forms. Like Parmenides who wanted to have an unchanging element in his worldview, Descartes divided the ever changing material world from the spiritual world of Mind, Soul and God and this contributed to the mind-body problem that persists to this day.

Another effect of alphabetic writing and deductive logic is the notion of the linear chain of cause and effect and hence reductionism, whereby all phenomena can be reduced to a simpler or more basic one implying that the whole is merely the sum of its parts just as the alphabet reduces all words to their basic phonemes. 


\section{The Reversal of the Alphabet Effects}

As McLuhan (1962) [6] long ago pointed out with electrically configured information the dominance of visual space wanes giving rise to the re-emergence of acoustic space and tribal sensibilities. He suggested that with electrically configured information, the reversal of the alphabet effects of: (1) Duality; (2) Reductionism; (3) the suppression of ground; and (4) the dominance of linear cause and effect thinking, would begin to take hold.

He noted that, "The electric implosion now brings oral and tribal ear-culture to the literate West ... [The] very much greater speedup, such as occurs with electricity, may serve to restore a tribal pattern of intense involvement [6] (pp. 38 \& 58)". McLuhan refers to the radio as the tribal drum with the power to "retribalize mankind, [with] its almost instant reversal of individualism into collectivism, Fascism or Marxism [6] (p. 265)".

The separation of figure and ground that alphabetic writing gave rise to also began to reverse with electrically configured information. McLuhan for one reversed the role of figure and ground in his analysis of the effects of media and technology. He wrote:

My writings baffle most people simply because I begin with ground and they begin with figure. I begin with effects and work round to the causes, whereas the conventional pattern is to start with a somewhat arbitrary selection of 'causes' and then try to match these with some of the effects. It is this haphazard matching process that leads to fragmentary superficiality. As for myself, I do not have a point of view, but simply work with the total situation as obvious figures against hidden ground. [7] (p. 478)

The idea of reversal is a key to cracking the McLuhan Code, i.e. to make sense of the special way he used phrases like figure/ground and reversal. He worked backwards from effects to their causes and from the ground or environment of media to the figure of their content. He used this technique to understand the future. He once wrote, "We look at the present through a rear view mirror. We march backwards into the future". Rather than focusing on the figure of the future through speculating he carefully studied the ground of the future, which is the present and the past. He said, "I've always been very careful never to predict anything that had not already happened [8] (p. 172)".

McLuhan (1962) [6] wrote about the reversal of cause and effect as early as 1962 in Understanding Media. Another aspect of the alphabet effect was the consideration of the linear sequence of cause followed by effect which McLuhan observed to have been reversed.

The Nemesis of Creativity ...

$\mathrm{N}$. Whitehead ... explained how the great discovery of the nineteenth century was the discovery of the technique of discovery. Namely, the technique of starting with the thing to be discovered and working back, step by step, as on an assembly line, to the point at which it is necessary to start in order to reach the desired object. In the arts this meant starting with the effect and then inventing a poem, painting, or building that would have just that effect and no other. [6] (p. 68)

McLuhan employed the same techniques in his analysis of the effects of technology: "The way to study the effects, for example, if you wanted to study what the motor car was, you might find out more from what it did to the environment and the community [8] (p. 90)".

\section{The Reversal of the Alphabet Effects in the Sciences}

The reversals of cause and effect and figure and ground signaled by McLuhan also began to happen in the world of science with the General Systems Theory of Ludwig von Bertalanffy (1968) [9], von Uexküll's (1926) [10] introduction of the umwelt for living organisms as well as the formulation of complexity, chaos and emergence theories. McLuhan read von Bertalanffy and von Bertalanffy read McLuhan. Each was aware of the other's work. We are not suggesting that there was a direct causal relationship in their work. It is just that each found the other's work reinforced their own ideas. 
The next set of examples of reversals of the alphabet effect in science took place largely after McLuhan's death in 1980, so they had no influence on him and, for the most part, the work of these scientists were not influenced by McLuhan's work either, but as we shall demonstrate there was a certain parallel between their work and his.

Von Bertalanffy's General Systems, complexity theory, chaos theory and emergence are closely related in that in each of these approaches there exists a supervenient system whose properties are not the product or sum of the properties of the components of that supervenient system, but are a result of the interactions of the components among themselves and with the system as a whole. We will show that the description of supervenient or emergent systems incorporates the reversal of the following: cause and effect, reductionism, the separation of figure and ground, and visual space, each a product of the alphabet effect.

An example of a supervenient or emergent system to those not familiar with the notion is a human being who is composed of billions of cells. The properties of the human being as a whole are not just the properties of his or her cells but the way those cells are organized and the way those cells interact with each other which are controlled by the needs of the human being as a whole.

The human being's needs cause (top down) the cells to behave as they do while at the same time the cells cause (bottom up) the human being to behave as he or she does. One cannot identify the causes and the effects of the supervenient system and its components nor can one separate the causes from the effects or the effects from the causes. The supervenient system as a whole and its components relate to each other as both cause and effect and hence we have a reversal of cause and effect just as McLuhan suggested. The reason for the claim of a reversal of cause and effect within supervenient systems is that it is not possible to separate the bottom up causality of the components creating the system from the top down causality of the system acting on and controlling its components. The top down and bottom up causalities are simultaneous and cannot be separated into a linear sequential chain of one cause resulting in one effect. The space in which the supervenient or emergent system operates is metaphorically acoustic space because the effects are coming from all directions at once, both from bottom up and from top down.

One also cannot separate figure from ground. The organs, the cells, the human organism as a system cannot be divided into a figure and a ground. Is the figure the whole human and the ground the cells or the organs? Or with a focus on the organs of the human body are the organs the figure and the ground is the cells? None of these divisions make sense. The supervenient system is both figure and ground and its components are also figure and ground. The figure of the system is the ground for the components and the figure of the components are the ground for the system. The figure and ground are not only reversed they are actually obliterated. One cannot separate the top down causality of the human system on its organs and cells from the bottom up causality of the organs and cells on the whole human. The system and its components are interlinked and the components among themselves are also interlinked and the system as a whole and its components are in interplay with each other. This interplay of the system and its components is very much like the description of the interaction and interplay of figure and ground that M. and E. McLuhan (1988) [2] (p. 5) described and which we quoted above.

Jakob von Uexküll (1926) [10] introduced the notion of the umwelt of an organism, which is that part of the environment that an organism interacts with in order to survive. Here we have another example of the interplay of figure and ground characteristic of acoustic space. The umwelt is that part of the general environment or ground in which the figure of the living organism operates. There must be an umwelt for an organism to exist and there must be an organism for an umwelt to exist or for that umwelt to be defined. The umwelt creates the organism by providing the resources it needs to survive and the organism creates the umwelt in the sense without the organism there would not be an umwelt. The figure of the organism and its umwelt or ground in which it operates are in a dynamic interplay with each other. 
Another approach that incorporates the reversal of cause and effect and hence the reversal of the alphabet effect is the Process Ecology approach of Robert Ulanowicz (2009) [11] described in his book, A Third Window: Natural Life Beyond Newton and Darwin. "Process ecology" is a way of explaining in a non-reductive terms the origins of life, the behavior of the ecosystems of living organisms and emergent processes in general. Process ecology is the third window for Ulanowicz superseding the first window of Newton's physics, which is time reversal invariant and universal and the second window of Darwinian evolution, which introduces history as a factor in the evolution of the species. Darwin retains elements of Newton especially in his approach to species that he deals with as though they are static.

Ulanowicz (2009) [11] (pp. 74-75) specifically introduces the notion of the reversal of cause and effect in the following passage:

A configuration of processes can, as a whole, strongly affect which objects remain in the system and which pass from the scene. This observation, inverts to a degree, the conventional wisdom that it is objects that direct processes. The processes, as a union, make a palpable contribution toward the creation of their constituent elements. This reversal of causal influence lies at the crux of process ecology, and it extirpates the Newtonian stricture of closure.

Reductionists under the spell of the alphabet effect fully embrace deductive logic and this explains why they are unable to deal with process ecology and systems in which cause and effect do not follow a linear one thing at a time process as is the case with alphabetic writing. It is not the case that with the reversal of cause and effect that we are abandoning the notion that cause and effect operate, rather we embrace the obvious idea that causes and effects are non-linear. The effect of each cause has an effect back on the cause that created it. Cause A that creates an Effect B, and is then acted upon by the Effect $B$ which changes A which changes B once again, which Changes A again and so on and so forth. This is a form of binary duality (Lior Lerman private communication) [3].

\section{Conclusions}

The alphabet effect has been revisited in light of the new patterns that emerge when the figure of the alphabet is viewed in the ground of the new digital environment. The pattern of human thought that emerges in the age of electric and digital information is quite different than the pattern of human thought when the alphabet and movable type print alone dominated the communication of information. We are not suggesting that there is a causal connection between media and the forms of human thought less we be accused of being technological determinists. We do maintain, however, that whatever the mechanism is, that the parallel of the patterns of media dynamics, on the one hand and human thought and their organization of information, on the other hand, is quite striking. Media effect the thoughts of their users and the thoughts of their users effect the media they use in a non-linear way as has been described in General Systems Theory; in chaos, complexity and emergence theory; in Ulanowicz'z process ecology; and in McLuhan's media ecology.

Acknowledgments: I want to thank Lior Lerman for her contribution to this article which would not have been written if I had not spoken with her at the Media Ecology Association conference in Bologna. Her insights into the nature of the alphabet effect have been incorporated here and cited as private communication.

Conflicts of Interest: The authors declare no conflict of interest.

\section{References}

1. McLuhan, M.; Logan, R.K. Alphabet, Mother of Invention. Et Cetera 1977, 34, 373-383.

2. McLuhan, M.; McLuhan, E. Laws of Media: The New Science; University of Toronto Press: Toronto, ON, Canada, 1988.

3. Lerman, L.; London, UK. Private communication, 2016.

4. Logan, R.K. Figure/Ground: Cracking the McLuhan Code. E-Compós Brasília 2011, 14, 1-13. 
5. Philoctetes. Parmenides II. Available online: http://philoctetes.free.fr/parmenides.htm (accessed on 15 November 2016).

6. McLuhan, M. The Gutenberg Galaxy; University of Toronto Press: Toronto, ON, Canada, 1962.

7. Molinaro, M.; McLuhan, C.; Toye, W. (Eds.) Letters of Marshall McLuhan; Oxford University Press: Toronto, ON, Canada, 1987.

8. McLuhan, M.; McLuhan, S.; Staines, D. Understanding Me: Lectures and Interviews; McClelland and Stewart: Toronto, ON, Canada, 2003.

9. Von Bertalanffy, L. General Systems Theory: Foundations, Development, Applications; George Braziller: New York, NY, USA, 1968.

10. Von Uexküll, J. Theoretical Biology; Harcourt, Brace \& Co.: New York, NY, USA, 1926.

11. Ulanowicz, R. A Third Window: Natural Life beyond Newton and Darwin; Templeton Foundation Press: West Conshohocken, PA, USA, 2009.

(c) 2017 by the author; licensee MDPI, Basel, Switzerland. This article is an open access article distributed under the terms and conditions of the Creative Commons Attribution (CC-BY) license (http:/ / creativecommons.org/licenses/by/4.0/). 